\title{
RETRACTED ARTICLE: Numerical Simulation of Cracking Propagation of Asphalt Concrete Beam
}

\author{
Xiaojing Zhang
}

Submitted: 5 June 2017 / Published online: 13 September 2017

(c) ASM International 2018

The author has retracted this article, Numerical Simulation of Cracking Propagation of Asphalt Concrete Beam, https://doi.org/10.1007/s11668-017-0307-2, due to data calculation errors made during the preparation of the manuscript which render the conclusions invalid. The author agrees to this retraction.

The online version of this article contains the full text of the retracted article as electronic supplementary material.

Electronic supplementary material The online version of this article (https://doi.org/10.1007/s11668-017-0307-2) contains supplementary material, which is available to authorized users.

X. Zhang ( $\square)$

School of Civil Engineering, Southwest Jiaotong University, No.

111, North 1st Section, 2nd Ring Road, Chengdu 610031,

Sichuan, China

e-mail: 249921359@qq.com

\section{Zhang}

Sichuan Expressway Construction \& Development Corporation, No. 90, West 1st Section, 2nd Ring Road, Sichuan Expressway Building, Chengdu 610041, Sichuan, China 